\title{
Development of a wind turbine gearbox virtual load sensor using multibody simulation and artificial neural networks
}

\author{
Baher Azzam ${ }^{1}$ (D) $\cdot$ Ralf Schelenz ${ }^{1}$ Björn Roscher ${ }^{1}$ Abdul Baseer ${ }^{1} \cdot$ Georg Jacobs $^{1}$ \\ Received: 30 November 2020 / Accepted: 4 March 2021 / Published online: 29 March 2021 \\ (c) The Author(s) 2021
}

\begin{abstract}
A current development trend in wind energy is characterized by the installation of wind turbines (WT) with increasing rated power output. Higher towers and larger rotor diameters increase rated power leading to an intensification of the load situation on the drive train and the main gearbox. However, current main gearbox condition monitoring systems (CMS) do not record the 6-degree of freedom (6-DOF) input loads to the transmission as it is too expensive. Therefore, this investigation aims to present an approach to develop and validate a low-cost virtual sensor for measuring the input loads of a WT main gearbox. A prototype of the virtual sensor system was developed in a virtual environment using a multi-body simulation (MBS) model of a WT drivetrain and artificial neural network (ANN) models. Simulated wind fields according to IEC 61400-1 covering a variety of wind speeds were generated and applied to a MBS model of a Vestas V52 wind turbine. The turbine contains a high-speed drivetrain with 4-points bearing suspension, a common drivetrain configuration. The simulation was used to generate time-series data of the target and input parameters for the virtual sensor algorithm, an ANN model. After the ANN was trained using the time-series data collected from the MBS, the developed virtual sensor algorithm was tested by comparing the estimated 6-DOF transmission input loads from the ANN to the simulated 6-DOF transmission input loads from the MBS. The results show high potential for virtual sensing 6-DOF wind turbine transmission input loads using the presented method.
\end{abstract}

\section{Entwicklung eines virtuellen Lastsensors für Windturbinengetriebe mittels Mehrkörpersimulation und künstlicher neuronaler Netze}

\section{Zusammenfassung}

Steigende Nennleistungen sind ein aktueller Entwicklungstrend in der Windenergieanlagentechnologie. In Kombination mit größeren Rotordurchmessern führt dies zu einer veränderten Belastungssituation des Antriebsstrangs und insbesondere des Hauptgetriebes von Windenergieanlagen. Aufgrund von hohen Kosten messen aktuell am Markt verfügbare Hauptgetriebe-Zustandsüberwachungssysteme diese veränderte Belastungssituation der Getriebeeingangslasten in 6 Freiheitsgrade (6-DOF) bisher nicht. Ziel dieser Untersuchung ist es daher, einen Ansatz zur Entwicklung und Validierung eines kostengünstigen virtuellen Sensors zur Messung der Eingangslasten eines WEA-Hauptgetriebes vorzustellen. Ein Prototyp des virtuellen Sensorsystems wurde in einer Modellumgebung unter Verwendung eines Mehrkörpersimulationsmodells (MKS) eines WEA-Antriebsstrangs und künstlicher neuronaler Netze (KNN) entwickelt. Simulierte Windfelder gemäß IEC 61400-1, die eine Vielzahl möglicher Windbedingungen abdecken, wurden generiert und auf ein MKS-Modell einer Vestas V52 Windenergieanlage angewendet. Die V52 Windenergieanlage hat ein am Markt häufig auffindbares schnelllaufendes Antriebsstrangkonzept mit Vierpunktlagerung. Die MKS-Windfeld-Simulationen wurden verwendet, um Zeitreihendaten für das Training des virtuellen Sensor-Algorithmus (das KNN-Modell) zu generieren. Im Anschluss an das Training erfolgte der Test des entwickelten virtuellen Sensor-Algorithmus indem die vom KNN geschätzten 6-DOF-Getriebeeingangslasten mit den simulierten 6-DOF-Getriebeeingangslasten des MKS verglichen wurden. Die Ergebnisse zeigen ein hohes Potenzial für die hier vorgestellte Methode zur Messung von 6-DOF-Getriebeeingangslasten mithilfe eines virtuellen Sensors.

Baher Azzam

baher.azzam@cwd.rwth-aachen.de
1 Center for Wind Power Drives, RWTH Aachen University, Campus-Boulevard 61, 52074 Aachen, Germany 


\section{Introduction}

The development in the field of wind energy has been characterized by the installation of new wind turbines with increasing rated power and the repowering of old turbines and wind farms [1-3]. As a result, the load situation in the drivetrain components in a wind turbine (WT) is intensifying [3]. Higher towers and larger rotor diameters result in higher power as well as higher torsional loads on the WT drivetrain. The torsional load is superimposed by the aerodynamic turbulence, which is characterized by both the tower height and location dependencies $[4,5]$. Thus, the load situation within the drivetrain has a time-variant and unpredictable dynamic, which has a strong influence on the utilization of individual components. This results in deviations between the design load spectra and the actual load spectra occurring in operation $[5,6]$. Such deviations could cause faster damage accumulations in drivetrain components, resulting in unexpected maintenance and increased downtime [5].

Additionally, the limited availability of space for wind farms due to logistical problems or social restrictions gave rise to a trend to increase the number of WTs per wind farm [5]. As a result, investigations showed that the operating conditions of WTs within a wind farm can be strongly location dependent [5, 7]. For example, WTs of the same type within a wind farm can have uneven overall utilization and component utilization [5]. Therefore, with the development of larger WTs and more densely packed wind farms, the need for monitoring the load situation within the WT drivetrain rises in order to gain a more accurate impression on component utilization and reduce the likelihood of unplanned downtime.

One of the drivetrain components that lead to the longest downtimes and most costly repairs is the gearbox [8,9]. Condition Monitoring Systems (CMS) are used to detect potential faults or initialized damages of gearbox components. These systems collect gearbox condition data and operating data, which are then evaluated and assessed. Although current CMSs are able to provide evaluation variables for the condition of the transmission and to detect possible damage at an early stage, currently deployed systems are not capable of measuring the input transmission mechanical loads [10]. For example, several investigations aimed to develop wind turbine CMS based on measurements of the low-speed shaft torque (hereinafter referred to as "shaft torque") [11-13]. However, developed systems for measuring shaft torque are yet to be deployed in new turbines [10]. This is mainly due to the high cost and low practicality of the measurement equipment needed for direct load measurements on the low-speed shaft [10]. However, the high potential of continuously monitoring transmission input loads such as shaft torque maintain the need for an affordable measurement system for measuring such loads. Therefore, this investigation aims to develop a prototype of a low-cost virtual sensor system for measuring transmission input loads in all 6 degrees of freedom (6-DOF).

The problem of measuring parameters of interest that are too costly or unpractical to directly sense requires novel sensor solutions to cost-effectively infer such parameters from alternative sources of information. With the recent developments in the machine learning field, virtual sensing has demonstrated high potential to bring down the cost and enhance the practicality of measurement systems in a variety of applications [14-18]. A virtual sensor allows a measurement system to indirectly measure a parameter of interest using a set of sensor values. The motivation is typically the significant difference in the cost of implementing the virtual sensor in comparison to directly measuring the parameter(s) of interest. With the help of machine learning (ML) techniques, virtual sensor algorithms can be trained using time-series data when both the parameter of interest (target variables) and the sensor values from a set of affordable sensors (predictor variables) were recorded. Thus, measurements of the parameter of interest, which is costly to directly measure, are still required to develop the virtual sensor algorithm. Further, it is also beneficial to iteratively experiment with different sensor setups (e.g. different measured parameters, different sensor locations) to identify the optimal set of affordable sensors to feed the virtual sensor algorithm. In this investigation for example, collecting the needed data to train a 6-DOF virtual sensor of transmission input loads would entail a resource-intensive measurement campaign of an operational WT drivetrain. In addition, equipping such a turbine with the necessary measuring equipment would be a difficult task to repeat when a different sensor configuration is to be experimented with during the prototyping phase of the envisaged virtual sensor. Therefore, reducing the resources required to prototype the envisaged virtual sensor system during the early development phase is necessary.

Time-series computer simulations, specifically MBS, offer a flexible platform capable of supplying the needed data to develop an ML-based virtual sensor. This paper will demonstrate a process for prototyping a virtual sensor for estimating 6-DOF WT transmission input loads using data obtained from a WT MBS model experiencing simulated wind fields. Simulated wind fields according to IEC 61400-1 [4] covering a variety of nominal wind speeds and load scenarios were generated and applied to an MBS model of a Vestas V52 wind turbine following a procedure outlined in Sect. 2.1. The turbine contains a high-speed drivetrain with 4-points main bearing arrangement, a common drivetrain configuration in the field. Foreseen in the project for comparison reasons is the design and test of a newly built three point main bearing arrangement for the V52. 
Fig. 1 Flow Chart of Virtual Sensor Development using MBS and ANN models

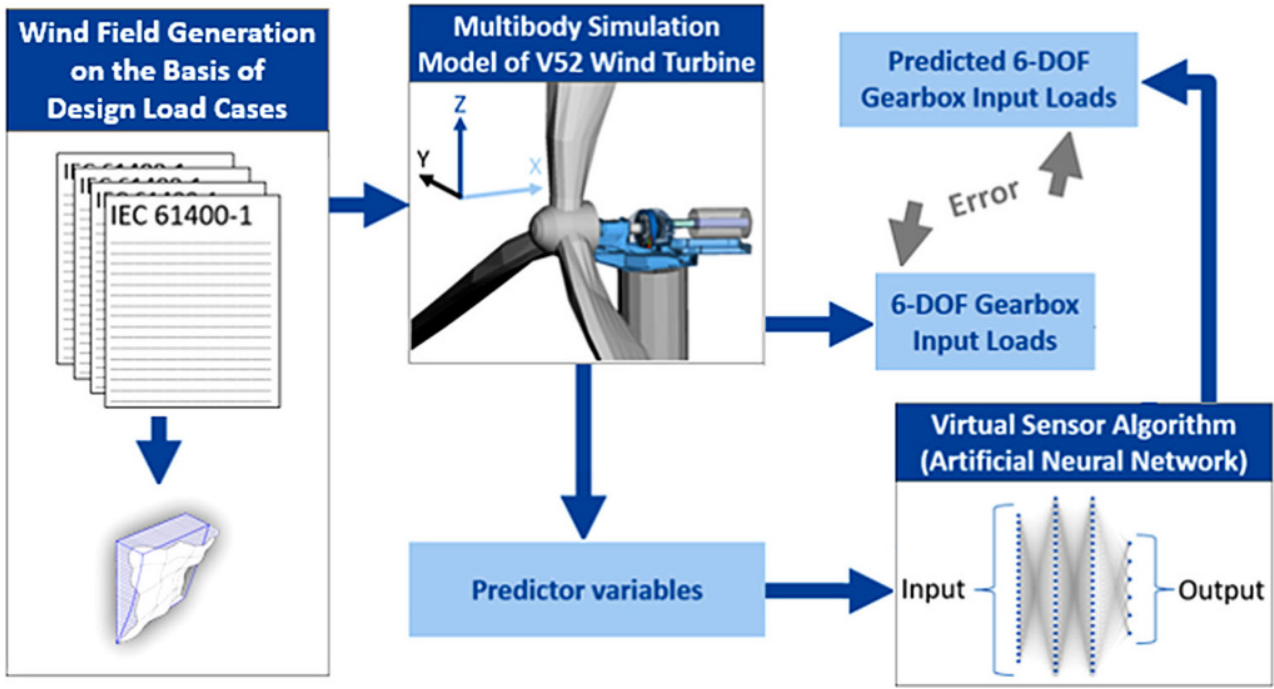

The simulation was used to generate time-series data of the target (output) and predictor (input) parameters for the development of the virtual sensor algorithm, in this case an ANN model. After the ANN was trained using the timeseries data collected from the MBS, the developed prototype of the virtual sensor algorithm was tested by comparing the estimated 6-DOF transmission input loads from the ANN to the simulated 6-DOF transmission input loads from the MBS. Fig. 1 provides an overview of the prototyping process leading to a trained and tested ANN-based virtual sensor algorithm.

To summarize, several investigations aimed to develop algorithms for directly or indirectly measuring WT transmission input loads $[10-13,19]$. On the one hand, the main obstacles for direct measurement solutions have been the low practicality and high costs of the needed sensor equipment [10]. On the other hand, virtual systems targeting the indirect measurement path have been hindered by the critical need for WT data in the form of measurements collected over different operating conditions in order to design and calibrate the envisaged systems [10]. This investigation addresses these needs by not only developing algorithms to perform virtual sensing of transmission input loads using practical measurement equipment, but also presenting a process to collect the needed data without performing an extensive measurement campaign, typically required to collect such data [10]. Therefore, this paper presents a holistic approach to the prototyping and development of a sensor system for WT transmission input load estimation which mitigates the main obstacles faced by previous investigations in this domain and brings this technology closer to field deployment.

This paper is organised as follows. Chap. 1 discusses the methods used in this investigation. Sect. 2.1 outlines the modelling and simulation approach, and the resulting data is described in Sect. 2.2 followed by an explanation of the data pre-processing steps in Sect. 2.3. Sect. 2.4 presents the data analysis performed, and Sect. 2.5 elaborates on considerations and challenges in practical implementation of the proposed method. Chap. 3 presents the results of the investigation followed by a discussion of the results in Chap. 4. The conclusions are outlined in Chap. 5.

\section{Methods}

\subsection{Modelling and simulation approach}

In order to generate time-series simulated data for training the envisaged virtual sensor algorithm, a model of the Vestas V52 turbine was constructed in a virtual MBS environment and subjected to simulated wind fields in accordance with the IEC 61400-1 standard [20]. Fig. 2 outlines the approach followed to perform the simulation and collect the simulated data. The main purpose of the simulation was to generate time-series simulated data covering the predictor and target parameters for the envisaged virtual sensor algorithm. Therefore, the level of detail in the simulation was tuned to ensure those parameters are accurately captured and to limit the error in the resulting data, e.g. force and torque estimations. Since the 6-DOF transmission input loads represent the target parameters, the rotor blades were first modelled in finite elements (FE) and then modally decomposed to the MBS environment [21]. Similarly, the tower was modally decomposed via the CraigBampton method and implemented in the MBS [22]. As the deflections and misalignments of the torque arms in all 6-DOF were also of interest as predictor parameters for the virtual sensor algorithm, the main shaft as well as the main frame and all pins within the gearbox and the planet car- 


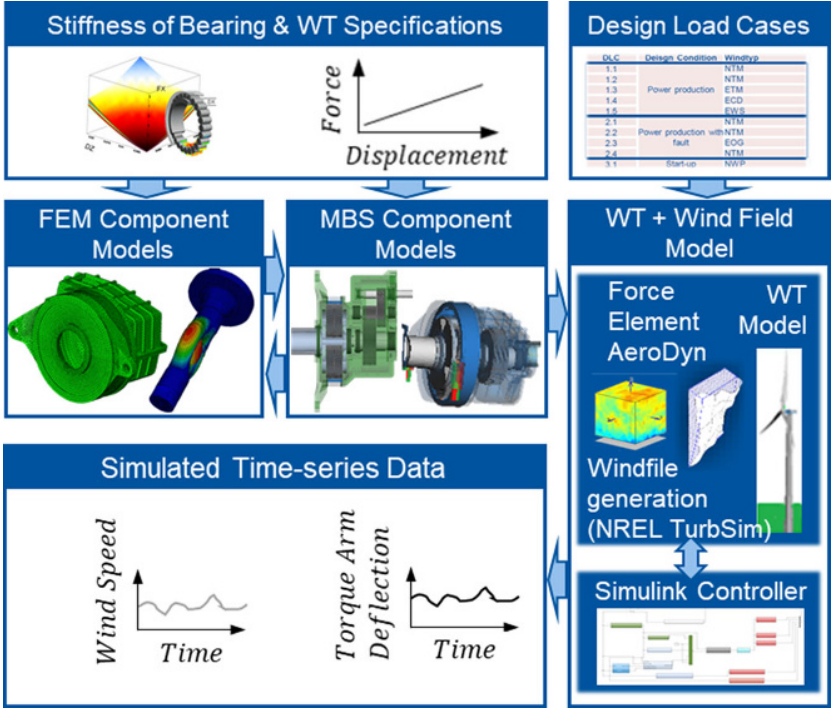

Fig. 2 Modelling and Simulation Approach

rier were modelled as flexible bodies in the MBS. In order to maintain the speed of the time-series simulation while covering the main deformation behavior of the flexible elements, the following procedure was applied. First, CAD model of elements (e.g. planet carrier) were simplified and transferred to FE environment. After that, the simplified CAD models were meshed using the FE method. The FE models were then modally decomposed to the MBS environment with the goal of covering the main eigenfrequencies and deformation behavior. The torque arms were simplified with a spring-damper force element. Similarly, the generator was connected to the main frame using springdamper force elements. The stiffnesses of the main bearing were calculated using the Bearin $\mathrm{X}^{\circledR}$ software and implemented as one dimensional characteristic curves for radial and axial directions using force elements. Additionally, micro-level flaws, e.g. material and tolerance imperfections, in WT components were not incorporated in the simulations.

The wind fields were simulated using Turbsim [23] and design load case calculations were performed via cosimulation with MATLAB. For those calculations, the AERODYN force element and a SIMULINK PI controller was used [24]. In order to demonstrate a proof of concept of the proposed method, three nominal wind speeds covering the cut-in, rated, and cut-out wind speeds of the Vestas V52 turbine were chosen for the wind field simulations in this investigation. Design load cases 1.1 and 1.2 were used to simulate six wind fields with a normal turbulence model and power production as the design condition. The wind fields covered two random seeds for each of the following nominal wind speeds: 3, 12, and $25 \mathrm{~m} / \mathrm{s}$. Each field was simulated for $600 \mathrm{~s}$.
Table 1 Predictor Parameters Collected from MBS Wind Turbine Model

Predictor Parameters

Left \& right torque arm displacements $(\mathrm{x}, \mathrm{y}, \mathrm{z})$

Left $\&$ right torque arm angular misalignments $(\alpha, \beta, \gamma)$

Four generator mount displacements (z)

Wind direction and speed

Three blade pitch angles

Generator speed

\subsection{Data description}

The predictor and target parameters were collected from the simulations for use as input and output variables, respectively, for the ANN-based virtual sensor algorithm. The collected target variables are the 6-DOF transmission input loads, and the predictor parameters are listed in Table 1 . The orientations of the $\mathrm{x}, \mathrm{y}$, and $\mathrm{z}$ axes with respect to the WT drivetrain are as illustrated in Fig. 1. In Table 1, wind speed refers to the average wind speed at hub height for each time step during the simulations. The hub height was chosen for the reason that wind speed measurement during operation is typically performed at nacelle height. In this investigation, the three blade pitch angles were identical. However, the decision to include three input blade pitch angles for the virtual sensor algorithm was made to enable training the algorithm on scenarios where offsets between pitch angles may be present. The sampling frequency of the parameters was $200 \mathrm{~Hz}$. Therefore, for each wind field, the MBS simulation generated a dataset containing 120,000 data points for 28 variables.

The data pre-processing steps implemented before training the ANN-based virtual sensor algorithm will be detailed in Sect. 2.3.

\subsection{Data pre-processing}

Before the collected data could be used to train and test the envisaged ANN model, certain preprocessing steps are necessary. Firstly, the data needed to be normalized to improve the speed of convergence when training the ANN [25]. This was performed on the data belonging to each variable in the datasets using the following formula:

$Z=\frac{X_{(i)}-u}{\sigma}$

Where $\mathrm{X}, \mathrm{u}$, and $\sigma$ represent the sample, mean of sample, and standard deviation of sample, respectively. The available data was then distributed among 3 datasets: training, validation, and testing datasets. The training set contained $45 \%$ of the data, while the validation and testing sets contained 5 and $50 \%$, respectively. 


\subsection{Data analysis}

After the data was preprocessed and split into the three datasets to be used for training, validating, and testing the ANN-based virtual sensor, the data analysis could be performed to reach the objective of this investigation. The Python programming language was used to perform the data analysis in this paper [26].

Feed-forward ANN models were trained to estimate the 6-DOF transmission input loads collected during the timeseries simulations, taking the predictor parameters, specified in Table 1, as input. The pre-processed data consists of 720,000 data points from six wind field simulations. Six ANNs were developed estimating one of the 6-DOF transmission input loads. As shown in Fig. 3, the process used to develop the ANN models started with an initial construction or architecture of the neural network which was iteratively improved through the process of hyperparameter tuning. The goal of hyperparameter tuning is to iteratively improve the accuracy of the trained model, when validated against the validation dataset, by altering the model's architecture. Some of the most influential hyperparameters on feed-forward ANN performance are the number of hidden layers, the number of nodes per layer, the types of activation functions, the type and parameters of regularization, the type of loss function, and the parameters of the optimizer function. For the training phase, the investigator must also decide parameters such as batch size and number of epochs of training which also highly influence the performance of the resulting ANN model. The hyperparameters were individually tuned for the six ANN models developed during this investigation until accuracy ceased to improve.

Table 2 lists some of the hyperparameters used in this investigation for training the top performing ANN models. The rectified linear unit (ReLu) [27] activation function was used after each hidden layer in all models due to its superior performance compared to activation functions such as the Sigmoid or the hyperbolic tangent (Tanh) activation functions [28, 29]. In addition, dropout layers were used during training as a countermeasure against overfitting. Dropout layers randomly switch off neurons, or nodes, at each update during training by setting the output value of the af-

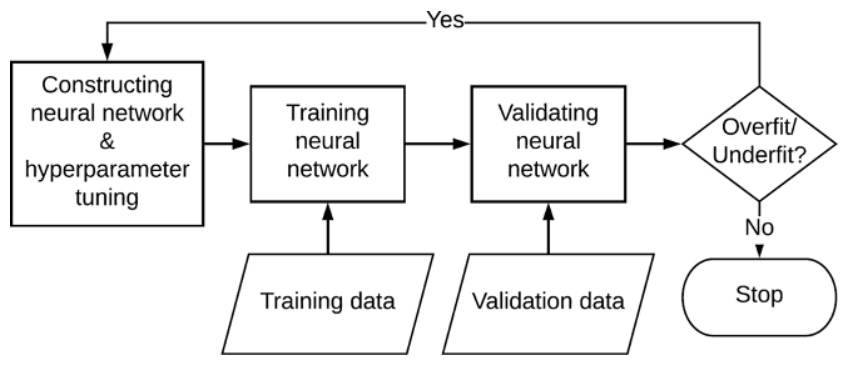

Fig. 3 Process Diagram for ANN Model Development
Table 2 Hyperparameters of Developed ANN Models for 6-DOF Load Estimation

\begin{tabular}{llll}
\hline $\begin{array}{l}\text { Model target parame- } \\
\text { ter }\end{array}$ & $\begin{array}{l}\text { Number of } \\
\text { hidden layers }\end{array}$ & $\begin{array}{l}\text { Nodes } \\
\text { per layer }\end{array}$ & $\begin{array}{l}\text { Number } \\
\text { of epochs }\end{array}$ \\
\hline $\begin{array}{l}\text { Transmission input } \\
\text { force (x-axis) }\end{array}$ & 8 & 1000 & 2 \\
$\begin{array}{l}\text { Transmission input } \\
\text { force (y-axis) }\end{array}$ & 8 & 1000 & 30 \\
$\begin{array}{l}\text { Transmission input } \\
\text { force (z-axis) }\end{array}$ & 5 & 400 & 30 \\
$\begin{array}{l}\text { Transmission input } \\
\text { moment (about x-axis) }\end{array}$ & 2 & 130 & 15 \\
$\begin{array}{l}\text { Transmission input } \\
\text { moment (about y-axis) }\end{array}$ & 5 & 400 & 30 \\
$\begin{array}{l}\text { Transmission input } \\
\text { moment (about z-axis) }\end{array}$ & 7 & 700 & 17 \\
\hline
\end{tabular}

fected nodes to zero [30]. The adaptive moment estimation (Adam) [31] was the optimization algorithm used to update the weights of the models during training to improve model accuracy, and the learning rate used for training the models was 0.001 .

During the testing phase, the developed models were tested on the previously unseen data from the test dataset. The resulting model estimations were evaluated using several metrics in order to thoroughly assess the errors of their estimations with respect to each of the 6-DOF transmission input loads. To give an impression of the absolute error in the respective load units, Eq. 2 [32] was used to calculate the mean absolute error (MAE) for each input load.

$M A E=\frac{\sum_{i=1}^{n}\left|y_{i}-\widehat{y}_{i}\right|}{n}$

Where $y_{i}, \hat{y}_{i}$, and $n$ represent the ith expected value, the ith estimated value, and the number of values in the dataset containing the target parameter, respectively.

In order to put the error into context, it is necessary to compare the deviations between estimations and expected values to the typical behaviours, or in this case, loading scenarios present in the available data. Due to the importance of this step in interpreting the resulting model errors, a twofold approach was implemented to investigate the relative errors of the model estimations. Firstly, the coefficient of determination, $\mathrm{R}^{2}$, was calculated for each of the 6-DOF loads by applying Eq. 3 to the target values from the test dataset and model estimations [33].

$R^{2}(y, \widehat{y})=1-\frac{\sum_{i=1}^{n}\left(y_{i}-\widehat{y}_{i}\right)^{2}}{\sum_{i=1}^{n}\left(y_{i}-\bar{y}\right)^{2}}$

Where $\bar{y}$ is the mean of the expected values of the target parameter, i.e. $\bar{y}=\frac{1}{n} \sum_{i=1}^{n} y_{i}$.

As can be read in Eq. 3, the error is calculated in relation to the term in the denominator which includes the expected 
value as well as the mean of the expected values of the target parameter from the test dataset.

A second approach to relative error was developed and implemented in order to provide more transparency and further evaluate the performance of the models. The approach begins with an extraction of relevant load statistics from the simulated loads at rated wind speed. The extracted statistics are minimum, maximum, and average values of the respective loads for each of the 6-DOF transmission input loads. Due to the nature of wind turbine input loads, a nuanced approach was needed in order to select the relative statistic for calculating relative error. For example, forces along the $\mathrm{y}$ axis (Fy) typically fluctuate around an average value close to zero. Thus, comparing the calculated MAE to the average value of Fy would result in an inflated error figure. Similarly, always selecting the maximum values of the 6-DOF loads to compare to the absolute error of the estimated loads would arguably result in an exaggerated impression of the skill of the models since it would result in relatively low errors. In addition, scaling the absolute error against the expected value for each data point as shown in Eq. 4 [34, 35 ] would result in extremely high error values when the expected value is zero.

$\mathrm{RMSRE}=\sqrt{\frac{1}{n} \cdot \sum_{i=1}^{n}\left(\frac{\hat{y}_{i}-y_{i}}{y_{i}}\right)^{2}}$

Therefore, a dedicated approach was developed to tackle these issues and calculate relative error using Eq. 5:

Load-Relative Error (LRE)

$$
=\frac{\sum_{i=1}^{n}\left|y_{i}-\widehat{y}_{i}\right|}{n \cdot \operatorname{median}\left(\left|y_{\max }\right|,\left|y_{\min }\right|,|\bar{y}|\right)}
$$

Where $y_{\max }$ and $y_{\min }$ are the maximum and minimum values of the target parameter, respectively.

By scaling the MAE against the median of the three statistics (minimum, maximum, average), an error can be calculated relative to a simple statistic representing the loads at rated wind speed while addressing the aforementioned issues with comparing error to only one statistic. As far as we know, this method of calculating relative error was developed during this investigation, inspired by the nature of the 6-DOF transmission input loads and the challenges therein. By using Eq. 6, a load-relative score (LRS) can be calculated comparable to the $\mathrm{R}^{2}$ score:

Load-Relative Score $($ LRS) $=1-$ LRE

\subsection{Considerations and challenges in practical implementation}

In this investigation, simulation data is used to train ANNbased virtual sensor algorithms; therefore, the accuracy of the developed virtual sensor is a function of the validity of the simulation model and its resulting data. Since absolute validity of a simulation model is refuted by most experts [36-39], the validity of a simulation model is only defined within the limits of the project and its intended application [40]. In other words, validation of a simulation model attempts to answer the following question: Is the model sufficiently accurate for its intended application? Indeed, the sufficiency of model accuracy from the perspective of its intended application is often used to define model validity [37, 41-43]. Different approaches to analyse the validity of simulation models have been proposed in literature with varying levels of comprehensiveness and associated costs [40]. The following are some examples:

- Micro-level examination and verification by system designers [41].

- Comparisons to real-world performance of the modelled system [41].

- A flow analysis of conserved quantities, such as heat and kinetic energy, through the model [44].

- Subjective assessment by the model development team on whether a model is valid based on results obtained during model development process [36].

When implementing the methodology proposed in this paper, investigators must gain a clear understanding of what is considered sufficient model accuracy with respect to the intended application of their envisaged virtual sensor. The degree of detail of the simulation model and the comprehensiveness of the validation analyses must fit the demands of the application. Therefore, the necessary quality of the MBS model for implementing the proposed method depends heavily on the intended application. Resource limitations must also be considered and an assessment needs to be made on whether the proposed method is a viable option for the intended application given the available resources for developing and validating the simulation models. It may be more affordable to develop the envisaged virtual sensor using data from real world experiments on the actual system as opposed to developing simulation models to provide sufficiently accurate data. However, this approach may become prohibitively costly if it would be a goal to investigate different potential sensor setups (e.g. different locations or types of sensors). This is due to the high cost of instrumenting a WT with all candidate sensor setups and performing sufficient experimentation with each setup. The proposed method would be beneficial in investigations which rely on real world measurement data to train the final virtual sen- 
sor algorithms by allowing for more affordable screening of potential sensor setups prior to costly real world experimentation.

Taking this project as an example, it is planned in the future to instrument and test two drivetrain configurations of the Vestas V52 as part of a measurement campaign aimed at further developing the envisaged 6-DOF transmission input loads virtual sensor. This presents a valuable opportunity to design and test a predefined sensor setup on actual systems. However, it also presents a challenge to find the optimal sensor setup prior to the test since it would not be possible to modify the sensor setup during the test; the drivetrain would be less accessible and pausing testing would cost valuable testing time. Therefore, the ability to prototype and screen different virtual sensor systems, albeit with less accuracy as compared to real world testing, provides a valuable opportunity to identify suitable sensor types and locations for the resource-intensive and less flexible real world test.

Lastly, the choice of the Vestas V52 for the first application of the proposed method is linked to the availability of a Vestas V52 drivetrain for the planned testing. Due to the age of the V52, design differences exist between its design and the design of more modern WTs e.g. more lightweight construction. The ANN-based virtual sensors in the proposed method use deformations and misalignments as input to sense transmission input loads. Therefore, it is expected that the lightweight construction of more recent turbines would at least maintain and more likely enhance the sensitivity of those parameters to experienced loads. This also may necessitate the modelling of some components in higher detail to reflect the additional deformability of such components during operation. As mentioned earlier, an assessment of model validity during the model development phase is vital for a successful implementation of the proposed method. A screening of different sensor setups may also lead to improvements in the accuracy of the ANN-based virtual sensor algorithms.

\section{Results}

As mentioned earlier, six feed-forward ANN models were trained to estimate each of the 6-DOF transmission input loads using the predictor parameters, listed in Table 1, as input. In addition to adjusting the number of nodes per layer, using the Rectified Linear Unit (ReLu) activation function and an Adaptive Moment Estimation (Adam) optimizer proved particularly useful in increasing model accuracy as well as training speed. The use of dropout layers was an effective measure against overfitting. After testing the developed models on the test dataset, the aforementioned error metrics were evaluated with respect to the model estimations of the target parameters. The calculated errors as well as the corresponding simulated loads statistics at rated wind speed are listed in Table 3 . The median value selected for the calculation of the LRS for each transmission input load is in bold to facilitate interpretation. The Tensorflow framework was utilized to implement the ANN algorithms [45].

The load relative error distributions of the estimated transmission input forces and moments are also plotted in Figs. 4 and 5, respectively. The LRE of the ith estimated value for each target parameter was calculated using Eq. 7:

$\operatorname{LRE}_{i}=\frac{y_{i}-\widehat{y}_{i}}{\operatorname{median}\left(\left|y_{\text {max }}\right|,\left|y_{\text {min }}\right|,|\bar{y}|\right)}$

\section{Discussion}

The results demonstrate high potential of the presented method for prototyping virtual sensor algorithms and sensor setups for estimating 6-DOF wind turbine transmission input loads. The mean absolute errors of the estimated forces and moments, listed in Table 3, are below the $\mathrm{kN}$ and $\mathrm{kNm}$ range, respectively, which corresponds to $\mathrm{R}^{2}$ scores as well as load relative scores above 0.9. Moreover, the load relative error distributions of the estimated loads shown in Figs. 4 and 5 demonstrate that the majority of estimations have an LRE close to zero. Therefore, the results of the developed virtual sensor prototype demonstrate the potential capability of feed-forward ANNs to estimate transmission

Table 3 Error Metrics of ANN Models Estimations \& Simulated Loads Statistics at Rated Wind Speed

\begin{tabular}{lllllll}
\hline $\begin{array}{l}\text { Target parameter: } \\
\text { transmission input load }\end{array}$ & $\begin{array}{l}\text { MAE (units: } \\
\text { N, Nm) }\end{array}$ & $\mathrm{R}^{2}$ & LRS & \multicolumn{5}{l}{ Simulated loads statistics at rated wind speed (units: N, Nm) } \\
\cline { 6 - 7 } & & & & Min. & Max. & Avg. \\
\hline Force (x-axis) & 170.07 & 0.96 & 0.95 & -7898 & 1050 & $\mathbf{- 3 2 2 2}$ \\
Force (y-axis) & 852.29 & 0.93 & 0.94 & $-17,972$ & $\mathbf{1 5 , 5 5 6}$ & -81 \\
Force (z-axis) & 792.25 & 0.96 & 0.98 & $-53,850$ & $-26,380$ & $\mathbf{- 4 1 , 0 7 4}$ \\
Moment (about x-axis) & 817.56 & 0.99 & 0.99 & $-380,056$ & $-41,669$ & $\mathbf{- 2 5 7 , 8 4 7}$ \\
Moment (about y-axis) & 548.87 & 0.95 & 0.98 & 22,881 & 32,429 & $\mathbf{2 7 , 3 6 8}$ \\
Moment (about z-axis) & 700.61 & 0.99 & 0.97 & 4555 & 45,827 & $\mathbf{3 0 , 1 2 4}$ \\
\hline
\end{tabular}




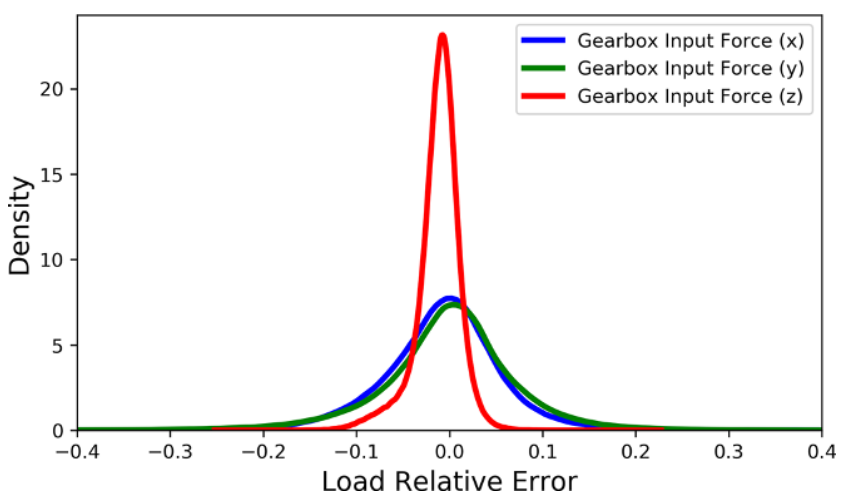

Fig. 4 Load Relative Error Distributions for Estimated Transmission Input Forces

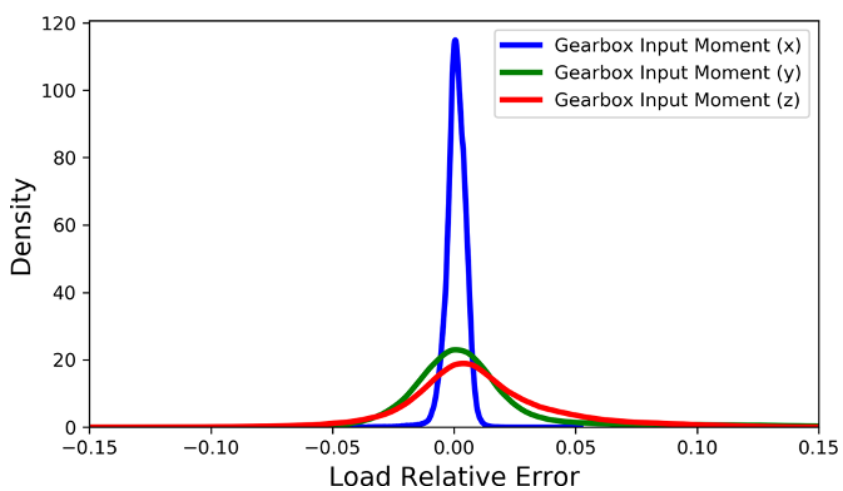

Fig. 5 Load Relative Error Distributions for Estimated Transmission Input Moments

input loads in a WT application without relying on costly, rotating measuring equipment such as telemetry systems. In addition, the flexibility offered by the MBS modelling environment used in this investigation can potentially reduce the resources needed for prototyping a virtual sensor for similar applications. The achieved results motivate further applications of the methodology presented in this paper in order to evaluate its transferability to other WT drivetrains and other wind fields based on different design load cases and wind speeds.

The predictor parameters, listed in Table 1, needed for the trained ANN models to estimate 6-DOF transmission input loads in a WT can be sensed using stationary sensors as well as sensors from the typical SCADA system in WTs. Displacement and angular misalignment parameters can be measured using stationary distance sensors mounted on the main frame or the gearbox housing. Despite the significant potential of enabling WT CMS to use WT drivetrain input loads such as shaft torque, such systems are so far limited to research and development environments [10]. One of the main obstacles hindering the deployment of such systems is the high cost and impracticality of the required measurement equipment. Therefore, the developed models could reduce the cost and increase the practicality of shaft load measurement, potentially enabling field-deployed CMS to use those measurements for fault identification in the future [10].

\section{Conclusion}

In this investigation, ANN-based virtual sensor algorithms were trained using simulated data obtained from a model of the Vestas V52 WT subjected to simulated wind fields in an MBS environment. The main conclusions are as follow:

1. The developed Feed-forward ANN models demonstrate promising potential for this technology in estimating 6-DOF WT transmission input loads using indirect, stationary measurement equipment as opposed to costly solutions, e.g. telemetry systems.

2. It is possible to collect the training data for developing an ANN-based virtual sensor for WT 6-DOF transmission input loads using the simulation approach outlined in this paper.

3. The flexibility offered by the presented methodology for virtual sensor development has the potential of dramatically reducing the resources needed for prototyping and testing virtual sensor systems compared to physical testing.

4. Due to the promising results achieved using the presented methodology, the authors aim to further test the methodology with different boundary conditions, e.g. different WT drivetrain configurations and different design load cases.

5. The load-relative score (LRS) was developed and applied during this investigation as a method of assessing the 6-DOF virtual sensor models estimation capabilities using selective scaling of a simple statistic representing the loads at rated wind speed.

Funding Open Access funding enabled and organized by Projekt DEAL.

Open Access This article is licensed under a Creative Commons Attribution 4.0 International License, which permits use, sharing, adaptation, distribution and reproduction in any medium or format, as long as you give appropriate credit to the original author(s) and the source, provide a link to the Creative Commons licence, and indicate if changes were made. The images or other third party material in this article are included in the article's Creative Commons licence, unless indicated otherwise in a credit line to the material. If material is not included in the article's Creative Commons licence and your intended use is not permitted by statutory regulation or exceeds the permitted use, you will need to obtain permission directly from the copyright holder. To view a copy of this licence, visit http://creativecommons.org/licenses/by/4. $0 \%$ 


\section{References}

1. Fraunhofer IEE (2018) Windenergie Report Deutschland 2018. Fraunhofer Verlag,

2. Wiser R, Millstein D, Bolinger M, Jeong S, Mills A (2020) The hidden value of large-rotor, tall-tower wind turbines in the United States. Wind Eng. https://doi.org/10.1177/0309524X20933949

3. McKennan R, Ostman v.d. Leye P, Fichtner W (2016) Key challenges and prospects for large wind turbines. Renew Sust Energ Rev. https://doi.org/10.1016/j.rser.2015.09.080

4. Deutsches Institut für Normung (2015) Windenergieanlagen - Teil 1: Auslegungsanforderungen. Deutsche Norm. VDE Verlag, Berlin

5. Roscher B, Werkmeister A, Jacobs G, Schelenz R (2017) Modelling of wind turbine loads nearby a wind farm. J Phys Conf Ser. https:// doi.org/10.1088/1742-6596/854/1/012038

6. Rommel D, Di Maio D, Tinga T (2020) Calculating wind turbine component loads for improved life prediction. Renew Energ. https://doi.org/10.1016/j.renene.2019.06.131

7. Cardaun B, Roscher B, Schelenz R, Jacobs G (2019) Analysis of wind-turbine main bearing loads due to constant yaw misalignments over a 20 years Timespan. Energies. https://doi.org/10.3390/ en12091768

8. Kotzalas M, Doll G (2010) Tribological advancements for reliable wind turbine performance. Philos Trans Math Phys Eng Sci. https:// doi.org/10.1098/rsta.2010.0194

9. Kim K, Parthasarathy G, Uluyol O, Foslien W, Sheng S, Fleming P (2011) Use of SCADA data for failure detection in wind turbines. ASME 2011 5th international conference on energy sustainability, Washington, DC

10. Perisic N, Kirkegaard P, Pedersen B (2015) Cost-effective shaft torque observer for condition monitoring of wind turbines. Wind Energy. https://doi.org/10.1002/we.1678

11. Yang W, Tavner P, Crabtree C, Feng Y, Qiu Y (2012) Wind turbine condition monitoring: technical and commercial challenges. Wind Energy. https://doi.org/10.1002/we.1508

12. Hameed Z, Hong Y, Cho Y, Ahn S, Song C (2009) Condition monitoring and fault detection of wind turbines and related algorithms: a review. Renew Sust Energ Rev 13:1-39

13. Lu B, Li Y, Wu X, Yang Z (2009) A review of recent advances in wind turbine condition monitoring and fault diagnosis. In: Power Electronics and Machines in Wind Applications Lincoln

14. Bin Ilyas E, Fischer M, Iggena T, Tönjes R (2020) Virtual sensor creation to replace faulty sensors using automated machine learning techniques. In: 2020 Global Internet of Things Summit (GIoTS) Dublin

15. Matusowsky M, Ramotsoela D, Abu-Mahfouz A (2020) Data imputation in wireless sensor networks using a machine learningbased virtual sensor. J Sens Actuator Netw. https://doi.org/10.3390/ jsan9020025

16. Zaidan MA et al (2020) Intelligent calibration and virtual sensing for integrated low-cost air quality sensors. IEEE Sens J. https://doi. org/10.1109/JSEN.2020.3010316

17. Williams A, Himschoot A, Saafir M, Gatlin M, Pendleton D, Alvord D (2020) A machine learning approach for solid rocket motor data analysis and virtual sensor development. In: AIAA propulsion and energy 2020 forum, virtual event

18. Roveda L, Bussolan A, Braghin F, Piga D (2020) 6D virtual sensor for wrench estimation in robotized interaction tasks exploiting extended Kalman filter. Machines. https://doi.org/10.3390/ machines 8040067

19. Perisic N, Pedersen B, Kirkegaard P (2012) Gearbox fatigue load estimation for condition monitoring of wind turbines. In: ISMA2012 international conference on noise and vibration Leuven

20. International Electrotechnical Commission (2019) IEC 61400-1. Wind turbines-part 1: design requirements
21. Berroth J (2017) Einfluss der Stelldynamik der Rotorblätter auf die Lasten der Blattverstellsysteme von Windenergieanlagen. Verlagsgruppe Mainz, Aachen

22. Craig R, Bampton M (1968) Coupling of substructures for dynamic analysis. AIAA J 6:1313-1319

23. Jonkman B (2009) Turbsim user's guide: Version 1.50. Technical Report No. NREL/EL-500-38230. National Renewable Energy Laboratory, Colorado

24. Bi L, Schelenz R, Jacobs G (2015) Dynamic simulation of full-scale nacelle test rig with focus on drivetrain response under emulated loads. In: Conference for Wind Power Drives Aachen

25. Sola J, Sevilla J (1997) Importance of input data normalization for the application of neural networks to complex industrial problems. IEEE T Nucl Sci. https://doi.org/10.1109/23.589532

26. van Rossum G (1995) Python tutorial. Technical Report CS-R9526. Centrum voor Wiskunde en Informatica (CWI), Amsterdam

27. Hinton G, Nair V (2010) Rectified linear units improve restricted Boltzmann machines. In: Proceedings of the 27th International Conference on Machine Learning (ICML-10) Haifa

28. Zeiler MD (2013) On rectified linear units for speech processing. In: Internationalconference on acoustics, speech and signal processing Vancouver

29. Dahl G, Sainath T, Hinton G (2013) Improving deep neural networks for LVCSR using rectified linear units and dropout. In: International conference on acoustics, speech and signal processing Vancouver

30. Srivastava N (2014) Dropout: a simple way to prevent neural networks from Overfitting. JMLR 15:1929-1958

31. Kingma D, Ba J (2015) Adam: a method for stochastic optimization. In: International Conference on Learning Representations (ICLR) San Diego

32. Sammut C, Webb G (2010) Encyclopedia of machine learning. Springer, Boston

33. Nagelkerke N (1991) A note on a general definition of the coefficient of determination. Biometrika. https://doi.org/10.1093/biomet/ 78.3.691

34. Göçken M, Özçalıcı M, Boru A, Dosdoğru A (2016) Integrating metaheuristics and Artificial Neural Networks for improved stock price prediction. Expert Syst Appl. https://doi.org/10.1016/j.eswa. 2015.09.029

35. Webber $\mathrm{H}$ et al (2017) Canopy temperature for simulation of heat stress in irrigated wheat in a semi-arid environment: a multi-model comparison. Field Crop Res. https://doi.org/10.1016/j.fcr.2015.10. 009

36. Sargent R (2010) Verification and validation of simulation models. In: Proceedings of the 2010 Winter Simulation Conference Baltimore

37. Babuska I, Oden T (2004) Verification and validation in computational engineering and science: basic concepts. Comput Methods Appl Mech Engrg. https://doi.org/10.1016/j.cma.2004.03.002

38. Law A (2007) Simulation modeling and analysis. McGraw-Hill, New York

39. Logan R, Nitta C (2004) Verification \& validation: process and levels leading to qualitative or quantitative validation statements. SAE Trans 113:804-816

40. Kutluay K, Winner H (2014) Validation of vehicle dynamics simulation models—a review. Vehicle Syst Dyn. https://doi.org/10.1080/ 00423114.2013 .868500

41. Carson J (2002) Model verification and validation. In: Proceedings of the Winter Simulation Conference San Diego

42. Schlesinger S (1979) Terminology for model credibility. SIMULATION. https://doi.org/10.1177/003754977903200304

43. American Institute of Aeronautics and Astronautics (1998) Guide for the Verification and Validation of Computational Fluid Dynamics Simulations (AIAA G-077-1998(2002)). AIAA. 
44. Tiller M (2009) Verification and validation of physical plant models. SAE International, Warrendale

45. Abadi $\mathrm{M}$ et al (2016) TensorFlow : Large-Scale Machine Learning on Heterogeneous Distributed Systems 